Savunma Bilimleri Dergisi

The Journal of Defense Sciences

Kasim/Nov 2017, Cilt/Volume 16, Say1/Issue 2.

ISSN (Bas111) : 1303-6831 ISSN (Online): 2148-1776

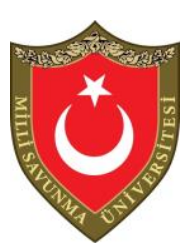

\title{
Çin Dış Politikasında İttifak Yapmama Prensibi: Akademik Tartışmalar
}

\author{
Nilgün ELİKÜÇÜK YILDIRIM ${ }^{1}$
}

\begin{abstract}
$\ddot{O} z$
Bu çalışmada Çin uluslararası ilişkiler akademisindeki ittifak yapmama prensibiyle ilgili tartışmalar ele alınmıştır. Çalışmanın temel iddiası, Çin akademisinde dış politika tartışmalarının hükümetin çizdiği çerçeveden daha dinamik ve karmaşık olduğudur. Uluslararası ilişkiler akademisyenlerinin dış politika yapımındaki önemi sadece hükümetin politikalarını desteklemelerinden değil aynı zamanda alternatif politika üretebilmelerinden kaynaklanmaktadır. Bu yüzden akademik tartışmalar ittifak yapmama politikasında bir değişikliğe gidilip gidilmeyeceğini analiz etmek için önemli bir fikri temel sağlamaktadır. Çinli akademisyenlerin ittifak yapmama prensibiyle ilgili görüşleri üç başlıkta ele alınmıştır. İlk grup, ittifak yapmamanin yararlarını savunan ortodoksidir. İkinci grup, ittifak yapmaya yönelik bir strateji değişikliğini savunan revizyonistlerdir. Üçüncü grup ise, prensibin tamamen terk edilmeyip yeni duruma uygun bir takım tamamlayıcı tedbirler alınması gerektiğini düşünen ılımlılardır. Bu gruplar içinde revizyonistlerinfikirleri Çin'in ittifak politikasındaki olası bir değişikliğin hangi yönde olacağı konusunda önemli ipuçları vermektedir. Ittifak yanlılarına göre potansiyel müttefik Rusya'dır. Revizyonistlerin fikirleri aynı zamanda Çin'de yükselen popüler milliyetçiliğinde bir yansımadır. Bu yüzden Çin'in ülke içinde yükselen milliyetçilik karşısında ittifak arayışı içine girmesi kaçınılmaz görünmektedir.
\end{abstract}

Anahtar Kelimeler: İttifak yapmama prensibi, Akademik Tartışmalar, Ortodoksi, Revizyonistler, Ilımlılar.

\footnotetext{
1 Arş. Gör., Gazi Üniversitesi, İ.İ.B.F, Uluslararası İlişkiler Bölümü,
} Ankara,nilgun_elikucuk@hotmail.com 


\title{
Non-alliance Principle in Chinese Foreign Policy: Academic Debates
}

\begin{abstract}
In this study, debates on the principle of non-alliance in Chinese international relations academy has been discussed. The main argument of the study is that foreign policy debates in the Chinese academy are more dynamic and complex than the framework drawn by government. The significance of international relations scholars in foreign policy making arise from not only because they support government policies, but also because they can produce alternative policies at the same time. Therefore, academic debates provide an important basis for analyzing whether a change in the policy of non-alliance will be pursued or not. Chinese scholars' views on the principle of non-alliance are addressed in three groups. The first group is orthodoxy who advocates the benefits of non-alliance. The second group is revisionists who advocate an alliance strategy. The third group is moderates who think that the non-alliance principle should not be abandoned completely. Within these groups, the ideas of the revisionists provide important clues about in which direction the possible changes in China's alliance policy will be. According to the revisionists, the potential ally is primarily Russia. The ideas of the revisionists are also a reflection of rising popular nationalism in China. Therefore, in the long term, it seems inevitable that Chinese foreign policy decision-makers are seeking alliances against this pressure coming from national field.
\end{abstract}

Keywords: Non-alliance Principle, Academic Debates, Orthodoxy, Revisionists, Moderates.

\section{Giriş}

Çin dış politikasında ittifak yapmama prensibi Deng Xiaoping'in ortaya attığı düşük profil stratejisinin (tao guang yang hui) önemli bir bileşenidir. İttifak yapmama politikasının temelinde 1950'li y1llarda uygulanan yibiandao (bir tarafa yönelmek) ve 1960'larda uygulanan liangge quantou daren (her iki tarafla da savaşmak) stratejisi vardır. Yibiandao stratejisiyle SSCB ile ittifak kurulmuş ve Çin iki kutuplu dünyada 
emperyalist kamp karşısında sosyalist bloğun önemli üyelerinden biri olmuştur. Liangge quantou daren stratejisi ise, Çin'in hem emperyalist (ABD) hem de revizyonist (SSCB) kampa karşı cephe almasıyla başlamıştır. 1960'lı yıllar Sino-Sovyet ayrılığı ve Sino-ABD cepheleşmesinin yaşandığ 1 ve Çin'in uluslararası sistemde yalnız kaldığı bir dönemdir (Cheng ve Zhan, 2009: 95-99). Fakat 1969'da yaşanan SinoSovyet sınırındaki silahlı çatışma, Çin'i büyük tehlikenin kuzeyden geldiğine ikna etmiştir. Bunun üzerine 1972 yllında ABD ile ilişkilerin normalleşmesi süreci başlamıştır. Fakat bu normalleşme ittifak ilişkisine dönüşmemiştir. Deng Xiaoping 1982 yılında dış politika stratejisinin bağımsızlık ve barışı hedeflediğini açıklamış ve ittifak yapmama politikası resmi olarak ilan edilmiştir (Campayo, 2016: 107). Bu politika ekonomik gelişme için uygun bir uluslararası çevre sağlamak, savaş riskini azaltmak ve Çin'in bağımsız egemenliğini herhangi bir ittifakın empoze edeceği kısıtlamalardan korumak için atılmış bir adımdır (Daguang, 2012). Deng Xiaoping, barışçıl kalkınmanın başarılması için uluslararası sistemde Çin lehine barışçıl bir uluslararası çevrenin yaratılmasının elzem olduğunu vurgulamaktadır. $\mathrm{Bu}$ yüzden düşük profil stratejisinde diplomasi, uluslararası alanda Çin ekonomisine hizmet edecek bir misyon olarak değerlendirilmiştir. Dış politika amaçları arasında uluslararası ekonomik düzeni değiştirmek ideali, siyasi düzeni değiștirmekten önceki hedef olarak gösterilmiştir (Xiaoping, 1994; Zhang, 2016).

Xiaoping'in halefleri Jiang Zemin ve Hu Jintao döneminde de kısmi değişikliklerle devam ettirilen düşük profil stratejisine yönelik ilk resmi meydan okuma ise Xi Jinping'in ortaya attığ ${ }_{1}$ başarı için mücadele (fen fa you wei) stratejisi ile olmuştur. Başarı için mücadeleden söz edilen ilk resmi konuşma bir bölgesel diplomasi konferansında yer almaktadır. Xi Jinping, 2013 yılı Ekim ayında politbüro daimi komitesinin bütün üyelerinin katıldığı bir bölgesel diplomasi konferansı düzenlemiştir (Cciced, 2013). Xinhua haber ajansına göre, bölgesel/periferik diplomasi konferansı önümüzdeki 5-10 yıl içerisinde Çin'in çevresindeki ülkelerle dış ilişkilerinin genel çerçevesini, stratejik amaçlarını ve temel prensiplerini belirlemeyi amaçlamaktadır. (Xinhua, 2013) Jinping konferanstaki konuşmasında Çinli diplomatlara başarı için mücadele (fen fa you wei, 奋发有为), daha aktif olma (gengjia jiji，更加积极) ve daha fazla inisiyatif alma (gengjia zhudong, 更加主动) prensiplerini benimsenmelerini şiddetle tavsiye etmiştir (Cciced, 2013, Sorensen, 2015: 66). Çevre diplomasisine rehberlik 
edecek temel kavramları ise dört karakter üzerinden açıklamaktadır: Qin (yakın olma), cheng (güvenilir olma), hui (yarar sağlama) ve rong (kapsayıcı olma).

Yeni stratejinin dört karakterinden ilki olan "Qin" yani yakın olma prensibi, sadece komşularla daha yakın ilişsiler kurmak değil aynı zamanda bölge meselelerine tarafsız kalmamak manasına gelmektedir. $\mathrm{Bu}$ yüzden Çin'in daha önce yapmadığı dost-düşman ayrımı, tarafsız duruşunun değişmesiyle daha çok dost edinmesi gerektiğine vurgu yapmaktadır (Xuetong, 2014: 167). Fakat başarı için mücadele stratejisinde ittifak yapmama prensibiyle ilgili doğrudan bir söylem değişikliğine gidilmemiştir. $\mathrm{Bu}$ yüzden akademik tartışmalar ittifak yapmama politikasında bir değişikliğe gidilip gidilmeyeceği konusunda önemli bir fikri temel sağlamaktadır.

\section{Çin Uluslararası İlişkiler Akademisinde İttifak Tartışmaları}

Çin dış politikasını analiz ederken ortaya çıkan temel sıkıntı, liderlerin fikir ve algılarını doğrudan ölçecek bir mekanizma olmamasıdır. Feng ve He uluslararası ilişsiler akademisyenlerinin tartışmalarını karar alıcıların zihinlerini okumak için bir "dolaylı ölçü" (proxy measure) olarak kullanmaktadırlar. Çünkü liderlerin algılarını detaylı olarak analiz etmek için kullanılacak daha güvenilir bir yöntem olmadığını söylemektedirler (Feng ve He, 2016: 14). Çalışmanın da temel iddiası, Çin akademisinde dış politika tartışmalarının hükümetin çizdiği çerçeveden daha dinamik ve karmaşık olduğudur. Akademi de birbirine zıt görüşte fikirlerin olması başlı başına bu camianın her zaman partiyle aynı şeyi düşünmediğini göstermektedir. Uluslararası ilişkiler akademisyenlerinin dış politika yapımındaki önemi, sadece hükümetin politikalarını desteklemelerinden değil, aynı zamanda alternatif politika üretebilmelerinden kaynaklanmaktadır.

Feng ve He, Çin uluslararası ilişkiler akademisyenlerinin dış politikadaki rolünü anlayabilmek için dört farklı fakat birbirini dışlamayan model kullanmaktadırlar. Bunlar epistemik topluluk modeli, serbest pazar modeli, sinyal verme modeli ve yansitma modelidir. Epistemik topluluk modeli, dış politika yapım sürecini doğrudan etkileyebilen ve hatta uluslararası işbirliklerinin koordinasyonunu sağlayabilen bir topluluğu ifade eder. Serbest Pazar modelinde ise, Çin uluslararası ilişkiler akademisyenleri bilgi üreticisi, hükümet ise tüketicidir. Serbest pazarda ortaya atılan teoriler, 
yeni fikirler ve politika önerilerinden, dış politika karar alıcılarının program ve fikirlerine uyanlar tercih edilir. Sinyal verme modelinde ise, uluslararasi ilişkiler akademisyenleri yeni fikirler ya da politika değişikliklerine gelebilecek toplumsal ve uluslararası tepkilerin test edilmesinde hükümet için sinyal verici rolü oynarlar. Son model ise yansitma modelidir. $\mathrm{Bu}$ modelde; uluslararası ilişkiler akademisyenleri Çin dış politikasının yönünü ve hatta iç politikadaki istikameti yansıtmada ayna işlevi görürler (Feng ve He, 2016: 9-14). Çalışmada, Çin uluslararası ilişkiler akademisindeki ittifak yapmama prensibi üzerine yapılan tartışmalarda bu modellerden hükümet politikalarının destekçisi olan epistemik topluluk ve alternatif politikalar üretmeye çalışan serbest Pazar topluluğu ele alınacaktır.

SSCB'nin dağılması ve Çin'in uluslararası sisteme entegrasyonu Soğuk Savaş döneminin güvenlik kaygılarını ortadan kaldırdığı için, ittifak yapmama prensibi Çin akademisinde uzun yıllar tartışmaya açılmamış bir konu olarak kalmıştır. Chen Zhimin 1999 yılında yayınlanan bir makalesinde Çin'in ABD'ye karşı ittifaka girmesini gerektirecek yakın bir tehdit olmadığından bahsetmektedir (Zhongping ve Jing, 2014: 11). 90'11 yıllarda Çin'in güvenliğine yönelik tehdit algısı olmadığı için sadece stratejik ortaklıkların kurulması akademi tarafından da yeterli görülmüştür. Fakat 2009 yılında Obama yönetiminin "Asya Ekseni (Asia Pivot)" stratejisini ortaya atmasi ittifak yapmama prensibini yeniden akademinin gündemine getirmiştir. İttifak tartışmaları, Çin'in İkinci Dünya Savaşı sonrası ABD'den hissettiği baskıyı Sovyetlerle ittifak yaparak bertaraf etmeye çalışması ya da, Sino-Sovyet ayrılığı üzerine ABD ile ittifaka girmesi gibi aynı tehdit algısıyla yapılmaktadır. Asya Ekseni, ABD'nin Asya-Pasifik bölgesinde hegemonyasını genişletmeyi amaçlayan bir strateji olarak değerlendirilmiş ve ittifak, güvenlik stratejilerinde tekrar bir seçenek olarak gündeme gelmiştir (Zhang, 2012: 130). Çinli akademisyenlerin yeni güvenlik tehditleri karşısında ittifak yapmama prensibiyle ilgili görüşleri üçe ayrılmaktadır. İlk grup, ittifak yapmamanın yararlarını savunan ve hükümet politikalarının destekçisi olan ortodoksi epistemik topluluğudur. İkinci grup, diğer devletlerle ittifak yapmaya yönelik bir strateji değişikliğini savunan revizyonistlerdir. Üçüncü grup ise, prensibin tamamen terk edilmeyip yeni duruma uygun bir takım tamamlayıcı tedbirler alınması gerektiğini düşünen 1lımlılardır (Ruonan ve Feng, 2017: 154). Revizyonistler ve 1lımlılar resmi söylemden bağımsız alternatif ittifak seçenekleri üzerinde duran serbest pazar topluluğu olarak ele alınacaktır. 


\section{Ortodoksi}

Çin'in ittifak yapmama prensibini savunanlar, askeri ittifakların maliyeti, Çin'in ittifak sistemi kurmak için yeterli gücü olmadığı ya da diğer ülkelerin Çin'le ittifak kurmak istemeyeceği gibi argümanlar ileri sürmektedirler. Ling Shengli, Soğuk Savaş’tan sonra güç kullanımının temel bir değişime uğradığını savunmaktadır. Askeri güç, ulusal çıkarları korumanın tek ya da en etkili yolu değildir artık. Büyük güç konumu, genellikle siyasi, ekonomik ve askeri güçten oluşan kapsamlı güce dayanmaktadır. Fakat bu güçler içinde askeri gücün ağırlığı azalmaktadır. Ayrıca, askeri ittifakların faydalarının yanında ağır maliyetleri de vardır. $\mathrm{Bu}$ yüzden Shengli, ittifak yapmamanın yükselen güç Çin için en uygun strateji olduğunu düşünmektedir (Shengli, 2013).

Qin Yaqing, ABD ile Çin arasındaki ulusal kapasite farklıkları ve güç boşluğu üzerinde durmaktadır. Çin'in uluslararası sistemdeki bir güç geçişini yönetmek, ya da sistemi değiştirmek için yeterli gücü yoktur (Yaqing, 2008: 38-39). İttifak yapmama prensibinin Çin diş politikasının temel özelliği olarak devam edeceğini iddia eden Yaqing, potansiyel müttefiklerin kim olacağı önemli olmaksızın, Çin'in yükselen güç kimliğini stratejik ittifaklarla destekleme eğilimi olası değildir (Yaqing, 2014: 308). Temel itibariyle resmi söyleme uygun bu epistemik topluluğun fikirleri dışında, eğer bir işbirliği yapılacaksa, ABD'ye karşı değil, ABD'yle yapılması gerektiğini düşünenler de vardır.

Wang Jisi, Obama'nın doğuya yönelik Asya Ekseni politikasının kasıtlı olsun ya da olmasın, Çin'i bir Doğu Asya ülkesi kategorisine sabitlediğini ve görüş açısını daralttığını ifade etmektedir. Ayrıca, Doğu Asya'daki Sino-ABD rekabeti, kolayca sıfır toplamlı oyuna dönüşebilecek bir niteliktedir. Eğer, Çin Batı yönünde ilerlerse (Batı Asya); yatırım, enerji, terörizm, nükleer silahların yayılmasının önlenmesi ve bölgesel istikrarın devamı gibi alanlarda ABD ile Çin arasındaki potansiyel işbirliği artacaktır. Ayrıca, Batı Asya'daki iki güç arasında çatışma çıkma ihtimali nerdeyse yoktur. Çin'in Doğu Asya'nın aksine Batı Asya'daki ülkelerle tarihsel bir husumeti de yoktur. Bundan dolayı Çin siyasi rekabette Batı Asya bölgesinde daha avantajlı durumda olacaktır (Jisi, 2014: 134). Jisi, Çin'in Doğu Asya'da ABD'yi dengeleme politikası güdüp ittifaklar kurmasından ziyade, Batı Asya'da varlık göstermesini tavsiye etmektedir. Çünkü Batı stratejisi jeo-politik rekabetin çatışma olmadan sürdürebilmesinin tek yoludur. ABD'ye karşı ittifak kurmak yerine, onunla işbirliği tavsiye eden 
diğer bir isim ise Zhu Feng'dir. Feng'e göre, tek kutupluluk sistemik bir kısıtlayıcıdır ve Çin'in yükselişini etkileyen önemli faktör, sistemin yapısının tek kutuplu olmasıdır. Çin diğer büyük güçlerle işbirliği yaparak ABD'yi dengeleme girişiminde bulunsa dahi, nihai olarak ABD ile uzlaşmaktan başka seçeneği yoktur. Çünkü Pekin için ABD’ye karşı koalisyon yapacak büyük güç bulmak neredeyse imkânsızdır. Çin ve ABD’nin yollarının kesiştiği tarih sadece ABD'yi yalnız süper güç değil, Çin'i de yalnız yükselen güç yapmıştır (Feng, 2008: 37-41). Ayrıca Çin'in karş1 ittifak yapabileceği Rusya ve $\mathrm{AB}$ gibi diğer büyük güçler $\mathrm{ABD}$ 'nin hegemonyası altında baskılanmaktadır. Rusya, Çin'in en büyük silah sağlayıcısı iken, yine de en ileri teknolojileri vermekte isteksizdir. Aynı şekilde Çin, AB'yi silah ambargosunu kaldırması konusunda ikna ederken, ABD'nin baskısı sonucu ambargo kaldırılamamaktadır (Feng, 2008: 43-44). Kuzey Kore meselesinde ise, Çin'in ABD ile işbirliği yapmasını meselenin çözümünde tek çıkar yol olarak gören Feng, nihai olarak ABD karşıtı bir ittifak sistemi yerine, ulusal çıkarları korumak için işbirliğine gitmeyi tavsiye eden savunmacı bir politika taraftarıdır (Feng, 2017).

İttifak meselesini savunmacı perspektiften inceleyen bir diğer isim Tang Shiping'dir. Shiping, Çin'in güvenlik stratejisini Mao dönemi saldırgan realizminden Xiaoping dönemi savunmacı realizmine evirilen bir sosyal süreç olarak değerlendirmektedir. Çin'in Mao sonrası dönemde savunmacı realizm benimsediğinin göstergeleri ise şunlardır; birincisi, Çin artık devrimci retoriğin tonunu düşürmüş ve diğer ülkelerdeki isyancıları (komünizm öğeleri içerse dahi) desteklemeyi bırakmıştır. İkincisi, Çin'in 1980'den beri uluslararası kurum ve kuruluşlara üye olması ve bu mekanizmaların kısıtlayıcılığına girmesi gönüllü olarak kabul edilmiştir. Son olarak, savunmacı realizmin ayırıcı özelliklerinden işbirliği yoluyla güvenlik, Xiaoping döneminde Çin güvenlik stratejisinin temel sütunlarından biri olmuştur. İşbirliği yoluyla güvenlik, hem komşularla iyi ilişkiler geliştirilmesine, hem de ASEAN bölgesel forumu ve Şangay İşbirliği Örgütünün kurulması gibi çok taraflı güvenlik organizasyonlarının hayata geçirilmesine vesile olmuştur (Shiping, 2008: 154-156). Shiping'e göre güvenlik stratejisi Çin'in uluslararası sistemin norm ve kurumlarıla yaşadığı etkileşime bağlı olarak değişen bir sosyal öğrenme sürecinin sonucudur. Çin'in bu süreçte uluslararası sistem ve çevresine yönelik öğrendiği, fark ettiği gerçekler ise şunlardır; bir, Çin birçok ülke ile komşudur ve bölgesi büyük güçlerin ilgi alanıdır. (ABD, Rusya, Hindistan ve Japonya gibi) Bu yüzden Çin'in coğrafi konumu, diğer ülkeler kolaylıkla 
karşı dengeleyici ittifak kurabileceği için, saldırgan realist strateji izlemeyi kısıtlamaktadır. İki, ABD'nin düşüşüyle ilgili net bir işaret olmadığ1 için, tek kutupluluğun kalıcı olacağı aşikârdır. Çin 90'lı yıllarda tek kutupluluğu geçici bir an olarak düşündüğü için çok kutupluluğa geçişi hızlandırmayı amaç edinmiştir. Fakat tek kutupluluğun değişmemesi, yapısal değişikliklerin kolay olmayacağını öğretmiştir. Üç, Çin gücü son 30 yılda giderek artsa da, hala sınırlı yeteneklere sahip fakir bir ülkedir. Çin'in artan ulusal gücü kendisini Mao dönemine göre daha güvende hissetmesini sağlamıştır. $\mathrm{Bu}$ güven duygusunun kaybedilmemesi için daha 1lımlı politikalar izlenmelidir. Dört, uluslararası sistem Hobbesçu dünyadan Lockeçu dünyaya doğru kesin bir şekilde evirilmiştir. Bundan dolayı, genişleme ya da fetih artık devletlerin güvenlik çıkarları için meşru bir seçenek değildir. Çin çok güçlü olsa dahi kaybettiği toprakları artık geri alma şansı yoktur. Bu yüzden travmatik geçmişiyle barışmalı ya da en azından onunla yaşamayı öğrenmelidir (Shiping, 2008: 156-157). Shiping'in Xiaoping döneminin savunmacı realizmiyle ilişkilendirdiği üç kavram analizinde temel önemdedir; 1lımlılık, kendi kendini kısıtlama ve güvenlik işbirlikleri. Fakat Çin'in iyi bir güvenlik çevresi yaratması için, bu üç kavramın diğer büyük güçler tarafından da benimsenmesi gerekmektedir. Eğer diğer büyük güçler de güvenlik çerçevelerini savunmacı realizme çevirirlerse güvenlik ikilemi diye bir şey kalmayacaktır (Shiping, 2003). Sonuç olarak Shiping, Çin'in tehdit algısını ittifakla değil, işbirliği ile bertaraf edeceğini savunmaktadır. Diğer savunmacı realist Feng gibi uluslararası sistemin yapısının tek kutuplu olduğu ve yakın zamanda değişmeyeceğini düşünmektedir. Aynı zamanda Çin'in kuracağı bir ittifak sisteminin karşılığını diğer büyük güçlerin dengeleyici ittifak sistemleriyle bulacağını düşünen Shiping'e göre, ittifak yapmama, güvenlik tehditlerini arttırmak yerine azaltmaya katkıda bulunacaktır.

\section{Revizyonistler}

İttifak taraftarı olan revizyonistler, Obama'nın Asya Ekseni politikasını, hem ekonomik hem de askeri olarak Çin'in yükselişini dengelemek ya da Çin'i çevrelemek için ortaya atılan bir stratejik dizayn olarak değerlendirmektedirler. Dai Xu, diğer büyük güçlerin ittifak ilişkilerine bakarak Çin'in de ittifak seçeneğini düşünmesi gerektiğini ifade etmektedir. ABD dünyada en çok müttefike sahip olan ülkedir. Diğer büyük güçlerin neredeyse hepsi hatta bağlantısız olarak bilinen Hindistan bile, 
çeşitli ittifak ilişkileri içindedir. Washington'un küresel hegemonya kurmaya çalıştığını düşünen $\mathrm{Xu}$, bu hegemonya mücadelesinde ABD'nin Avrasya'yı ana muharebe alanı Çin ve Rusya'yı ise nihai hedef olarak gördügüüü iddia etmektedir. Bundan dolayı Çin ve Rusya ABD'nin küresel imparatorluk stratejisine karşı “Büyük Avrasya İttifakı'nı kurmalıdırlar. Avrasya ittifakı kurulursa ABD ve Avrupa'ya olan ekonomik bağımlılık azalacak ve böylece daha çok siyasi otonomi elde edilecektir. Ayrıca bu ittifak güvenliği arttıracağı gibi, İran ve Pakistan gibi ülkeleri de bu ittifaka katılmaya teşvik edecektir (Xu, 2012).

Li Daguang, Çin'in ittifak yapmama politikasının, Soğuk Savaş dönemi Doğu-Batı antagonizmine dayalı ittifak ve ilişki biçimlerinin sonucu olduğunu ifade etmektedir. Fakat bu politika Çin'in dostluk ilişkisi kurmayacağı ya da bölgesel güvenlik organizasyonlarına katılmayacağ manasına gelmemektedir. Dostluk ilişkisi kurmak Çin'e karşı diğer büyük devletler tarafından oluşturulan çevreleme politikasının kırılması için oldukça yararlı olacaktır. Aksi durumda, Çin'in, güçlenirken dostlarının azalması aynı zamanda uluslararası alanda etki sahasının da azalmasına yol açacaktır. $\mathrm{Bu}$ da yumuşak gücün zayıflaması demektir. ABD'nin çeşitli alanlardaki ittifak ilişkilerinin yumuşak gücünü arttırdığını düşünen Daguang, Çin'in ittifak yaparak uluslararası alanda etki sahasını arttırabileceğinin altını çizmektedir (Daguang, 2012).

Çin'in ittifak yapması gerektiğini savunan diğer bir önemli isim Yan Xuetong'dur. Xuetong'a göre, ittifak yapma büyük güçlerin uluslararası alanda liderlik elde etmek için antik zamanlardan beri uyguladığı geleneksel bir stratejidir. İlkbahar ve Sonbahar Döneminde (M.Ö 722-481) yaşayan devlet adamı Guanzi'nin "bir devlet diğer devletlerin çoğunluğu ile dostluk ilişkisi kurarsa insancıl otorite olur, fakat yarısı ile dostluk ilişkisi içindeyse hegemon olur" sözleriyle ittifak kurmanın Çin tarihinde ahlaki bir temeli olduğuna dikkat çeker. Çin, ulusal dirilişi bir dış politika amacı olarak görüyorsa, 1982 yılından beri benimsediği ittifak yapmama politikasından vazgeçmelidir (Xuetong, 2014: 165). ABD'nin Asya-Pasifik'e yönelik eksen politikasını stratejik düzenleme olarak değerlendiren Xuetong, bölgede ABD ile Çin arasındaki mücadelenin gittikçe büyüyeceğini fakat bu mücadelenin Soğuk Savaş kalıpları içinde cereyan etmeyeceğini vurgulamaktadır. Savunmacı realistlerin aksine iki ülke arasında kurulacak stratejik güvenin bu mücadeleyi engelleyecek bir çözüm yöntemi olmadığını savunmaktadır (Xuetong, 2013). Xuetong'un savunmacı realistlerden ayrılan yönü; uluslararası sistemin yapısını tek kutuplu değil, iki kutuplu 
olarak görmesidir. Xuetong, ABD ile arasındaki güç boşluğunu dolduracak başka bir devlet olmadığı için, Çin'i iki kutuplu sistemin ABD ile birlikte temel aktörü olarak değerlendirmektedir. İki devlet arasındaki ilişkinin istikrarını belirleyen şeyler ise karşılıklı çıkarlar ve karşılıklı destek beklentisidir. Xuetong, Çin ile ABD arasındaki istikrar ilişkinin karakteristiklerini dört döneme ayırmaktadır. Buna göre, 1950-1970 arası dönemde bu ilişkinin karakteri husumet, 1971-1977 arası dönemde yüzeysel husumet (superficial enmity), 1978-1988 aras1 dönemde dostluk, 1995-2010 yılları arasında ise yüzeysel dostluk (superficial friendship) 'tur. Dostluk ve yüzeysel husumet döneminde iki devletin de lehine olan ortak çıkarlar (mutually favorable interest) aleyhteki ç1karlardan (unfavorable interest) daha fazladır. Yüzeysel dostluk ve husumet dönemlerinde ise, aleyhte çıkarlar ortak çıkarlardan daha fazladır. Dostluk ve yüzeysel dostluk ilişkilerinde iki tarafında birbirinden destek beklentisi yüksekken, düşmanlık ve yüzeysel düşmanlık ilişkilerinde destek beklentisi düşüktür (Xuetong, 2010: 281). Günümüzdeki ABD-Çin ilişkisini yüzeysel dostluk olarak tanımlayan Xuetong'a göre, yüzeysel dostluk ilişkisi iki devlet arasındaki aleyhte çıkarların fazla olması sebebiyle gerçek dostluğa göre daha istikrarsız bir ilişki biçimidir. ABD ile Çin'in temel çıkarlar konusunda saygılı olmaya dayalı yüzeysel dostluk ilişkisi, ABD'nin Tayvan'a silah satışı gibi konularda sadece söylemden ibaret kalmaktadır. Xuetong'a göre, ABD ile Çin arasındaki yüzeysel dostluk ilişkisinin siyasi temeli düşük profil stratejisine dayanmaktadır. Çin'in düşük profil ile ekonomik gelişme stratejisi izlemeye başlaması, siyasi ve askeri meselelerin göz ardı edilmesine yol açmıştır (Xuetong ve Qi, 2012: 122-123). Çin ve ABD'nin istikrarlı bir ilişki yürütebilmesi için yüzeysel dostluktan vazgeçilmesi gerektiğini belirten Xuetong, iki tür ilişkinin istikrar sağlayabileceğini vurgulamaktadır. Bunlar dostluk ve yüzeysel husumettir. İki ülke arasındaki güç mücadelesi Çin'in yükselişi dikkate alındığında gerçek bir dostluğa imkân vermemektedir. Bu yüzden daha gerçekçi alternatif yüzeysel dostluktan yüzeysel husumete geçilmesidir. Yüzeysel husumet yüzeysel dostluktan daha istikrarlıdır. Ayrıca, ikili ilişkilerin geliştirilmesine daha çok imkân tanımaktadır. Yüzeysel husumette, taraflar birbirlerinin düşman olarak tanımlamaktadır. Fakat ortak lehte çıkarları, aleyhte çıkarlara göre daha fazladır. Ayrıca her iki tarafın da birbirinden destek beklentisi düşük olduğu için yüzeysel dostluktaki gibi hayal kırıklıkları yaşanmayacaktır (Xuetong, 2010: 284). Çin ve ABD arasındaki yüzeysel husumet ilişkisinde ortak lehte çıkarlar, kültür ve ekonomi alanlarındadır. Alehyte çıkarlar ise, 
siyasi ve askeri alanlardadır. Aleyhte çıkarlar alanında yaşanan mücadele, her iki tarafindan net bir pozisyon almasıyla aynı zamanda istikrarın korunmasına yol açacaktır. ABD ve Çin arasındaki siyasi ilişkinin "siyasi mücadele" olarak tanımlanması iki taraflı ya da çok taraflı meselelerde beklenmeyen bir çatışmadan kaçınmayı sağlayacaktır. Güvenlik ilişkilerinin "askeri düşmanlar" üzerine kurulması da, ABD ile Çin arasında yaşanacak bir askeri çatışma tehlikesini azaltacaktır. Xuetong, Çin ve ABD arasındaki yüzeysel husumet ilişkisini önermesini siyasi alanda pozitif mücadele, askeri alanda önleyici işbirliği kavramlarıyla desteklemektedir. Pozitif siyasi mücadele, dünyaya $A B D$ ve Çin gibi iki gelişme modeli sunacak ve daha iyi bir dünya liderliği için seçme şansı verecektir. İki ülke arasındaki geliştirilecek önleyici güvenlik işbirlikleri ise, dünya barışına katkıda bulunacaktır (Xuetong, 2010: 285-290). Yüzeysel dostluğun dostmuş gibi yapmaya dayanan bir ilişki biçimi olduğunu düşünen Xuetong, her iki devletin de çıkarlar ve amaçlar konusunda net bir tavır almaları gerektiğini belirtmektedir. Çünkü yüzeysel dostlukta her iki tarafında farklı niyetlerinin olduğu bilindiği için stratejik güven kurulamamaktadır. Fakat yüzeysel husumette iki devletinde net tavır almaları, Soğuk Savaş dönemi gibi bir çatışma ortamı yaşanacağını düşündürmemelidir. ABD ile Sovyetler arasındaki mücadeleyi boks maçına benzeten Xuetong, ABD-Çin mücadelesine futbol maçı benzetmesini daha uygun görmektedir. İlki şiddet ile karakterize edilen bir mücadeleyken ikincisi, nadiren çatışmanın yer aldığ1 ve şiddeti öncelemeyen bir ilişki biçimidir (Xuetong ve Qi, 2012: 127). ABD ve Çin arasındaki mevcut yüzeysel dostluk ilişkisinin ne kadar süreceği ise iki kritere bağlıdır. Bir ABD ile Çin arasındaki ulusal güç boşluğunun hızla azalması, iki ve konumuz açısından daha önemli olanı ise, Çin'in ittifak yapmama politikasından vazgeçmesidir. Xuetong'a göre, Çin'in GSYİH'sı ABD'yi 10 yıl içinde geçebilir, fakat askeri olarak Çin'in ABD'yi yakalaması 15 yıldan fazla sürecektir. Eğer Çin ittifak yapmama politikasını değiştirirse, geliştireceği dostluk ilişkileri ABD ile arasındaki boşluğun kapanmasına yardımcı olacaktır. İttifak yapmama politikası devam ederse, Çin'in gücü ABD liderliğinde ittifakı kontrol etmeye yetmeyecektir. İttifak yapmama prensibinin devam etmesi ve diğer devletlere güvenlik alanında koruma sağlanmaması, Çin'in uluslararası alanda destek görmesini de zorlaştırmaktadır. Eğer Çin bir ittifak ağı kurarsa, ABD ile yüzeysel dostluk ilişkini devam ettirmesi de zorlaşacağı için, yüzeysel husumete geçilmesinde ittifak önemli bir köşe taşını temsil etmektedir (Xuetong ve Qi, 2012: 126). Xuetong, Xi Jinping'in ortak kader topluluğu çağrısını 
ittifaktan daha sıkı ya da gevşek bir birlik olması önemli olmaksızın en azından kurulacak askeri işbirlikleri için temel bir adım olarak görmektedir (Xuetong, 2014: 182).

\section{Ilımlılar}

İttifak yanlıları ve ittifak karşıtları arasında kalan bu grup, ittifak yapmama prensibinin tamamen terkedilmemesi gerektiğini düşünmektedirler. Ilımlıların ortaya attı̆̆ı fikirler ise başlıca şunlardır; ittifak yerine konulara özgü koalisyonlar (issue-specific), resmi olmayan yarı ittifak/ittifak benzeri (quasi alliance) oluşumlar ve stratejik ortaklıklar kurulması. Stratejik ortaklık fikri ittifak yerine üçüncü tarafi tehdit etmeyen bir işbirliği stratejisi öngörmektedir. Bu bağlamda aslında resmi söylemi takip eden bir epistemik topluluğun benimsediği fikirdir. Konulara özgü koalisyonlar ise, sadece güvenlik alanında değil ekonomi, politika gibi alanlara doğru genişletilebilecek ve spesifik mevzular üzerinde resmi olmayan işbirliklerinin benimsenmesidir (Ruonan ve Feng, 2017: 159-160). Yarı ittifak fikri ise, doğrudan askeri işbirliklerini ön plana çıkardığı için, ittifak yapmama ve ittifak yanlısı görüşlerin yanında önemli bir alternatif olarak yer almaktadır. Yarı ittifak fikrinin destekçilerinden Sun Degang, uluslararası güvenlik işbirliklerinde, devletlerin sadece resmi ittifaklara değil, gayri resmi güvenlik düzenlemelerine de dayalı bir strateji güttüklerini ifade etmektedir. Sun'a göre yarı ittifak, resmi kolektif savunma paktlarına değil bir ya da birden fazla uluslararası siyasal sistem arasında zımni mutabakata dayanan daimi ya da geçici gayri resmi güvenlik işbirlikleridir (Sun, 2011: 62).

Sun'a göre, yarı ittifakların altı özelliği vardır.

1. Büyüklük açısından iki taraflı ya da çok taraflı olabilir.

2. Egemen devletler ya da egemen olmayan aktörler tarafindan kurulabilir.

3. Yarı ittifaklar farklı devletlerin elitleri arasında zımni bir mutabakata bağlı olarak kurulabilir.

4. Yarı ittifaklar zımni, geçici ya da her ikisinin birlikte olduğu bir formatta kurulabilir.

5. Yarı ittifakların yönetimi askeri anlaşmalar yerine karşılıklı beklentiye dayanan ortak beyan, dostluk ya da işbirliği anlaşmalarına dayanır. 
6. Yarı ittifaklar doğası gereği üçüncü tarafı açıkça ya da dolaylı olarak hedef alan ekonomik, siyasi ya da kültürel değil askeri ve güvenlik işbirlikleridir (Sun, 2009: 68).

İttifak ve yarı ittifakın birbirinden ayrılan yönleri ise şunlardır; ilkinde taraflar güvenlik işbirliğinde karşılıklı bağımlı iken, ikincisinde, göreli olarak daha bağımsızdırlar. İttifakta mutabakat resmi askeri paktlarla sonuçlanırken, yarı ittifakta gayri resmi güvenlik düzenlemeleri ile yetinilmektedir. İttifakta işbirliği prensibi ortak savunma anlaşmalarıyla belirlenirken, yarı ittifakta işbirliği resmi bir koşula bağlanmayan karşılıklı beklenti üzerinden yapılmaktadır. İttifakta devletlerin egemenliğinin anlaşmalarla kısıtlanması söz konusuyken, yarı ittifakta daha az yetki devri vardır. Son olarak ittifakta işbirliğinin formu daha durağan, statik iken, yarı ittifakta zımni ve geçici anlaşmaların olması sebebiyle işbirliği daha dinamiktir (Sun, 2011: 65). Sun, Çin'in mevcut durumda ittifak yapmama prensibini değil yarı ittifak temelli bir dış politika stratejisi izlediğini iddia etmektedir. Yarı ittifak stratejisinin aynı zamanda bir diplomasi teorisi olduğunu savunan Sun, Çin'in güvenlik politikalarını "yarı ittifak diplomasisinin üç halkası" adını verdiği kavramsallaştırmayla açıklamaktadır. Bu kavrama göre ilk halka, Şangay İşbirliği Örgütü gibi çok taraflı organizasyonların içinde kurulacak yarı ittifaklardır. İkinci halka, Doğu Asya'nın önemli devletleriyle yeni model işbirliğine dayalı olarak kurulacak yarı ittifaklardır. Son halka ise, dostluk diplomasisi modelinin devam ettirilmesidir. Sun'a göre üç halka yarı ittifak diplomasisi ile Çin, uluslararası sistemde yalnız kalmayacak ve bu sayede büyük güçten dominant güç statüsüne geçebilecektir (Ruonan ve Feng, 2017: 160).

Shi Yinhong da Sun gibi Çin'in yarı ittifak stratejisi izlediğini düşünmektedir. Moskova'nın Batı'dan gelen baskıdan dolayı Pekin ile stratejik işbirliği geliştirmeye daha çok önem verdiğini düşünen Yinhong, Rusya ile Çin'in 2016 yılında Güney Çin Denizinde ortak tatbikat yapmasını askeri alanda işbirliğinin bir tezahürü olarak değerlendirmektedir. ABD'nin Çin ve Rusya'nın temel stratejik rakibi olduğunu ifade eden Yinhong, ABD'den gelen baskının Rusya ve Çin işbirliğini yarı ittifak seviyesine taşıdığını belirtmektedir (Sheng, 2016).

\section{Sonuç}

İttifak yapmama prensibini, askeri ittifakların maliyeti ya da ABD'ye karşı bir ittifak sistemi içine girilmesinin, kazançtan çok zarar getireceği 
gibi sebeplerle savunan ortodoksi grubu dışında ittifak yapılmasına açık ya da üstü kapalı olarak destek veren gruplar revizyonistler ve 1lımlılardır. Ilımlıların yarı-ittifak önerisi esas itibariyle hükümet politikalarına ters düşmemektedir. Çünkü zaten var olan Şangay İşbirliği Örgütü gibi işbirliklerinin teorik zemine oturtulması dışında bir politika alternatifi sunmamaktadırlar. Bu bakımdan revizyonistlerin fikirleri Çin'in ittifak politikasındaki olası bir değişikliğin hangi yönde olacağı konusunda önemli ipuçları vermektedir. İttifak yanlılarının üzerinde durduğu potansiyel müttefik öncelikli olarak Rusya'dır. Yan Xuetong, ne Çin'in ne de Rusya'nın düşman ve yabancı olarak görüldükleri için ABD liderliğindeki bir Batı ittifakına katılmayacağını ifade etmektedir. Bundan dolayı Çin ve Rusya arasında Batı ittifakından gelecek tehditlere karşı bir ittifak kurulmalıdır (Xuetong, 2012: 3). Rusya ile ittifakı destekleyenlere göre bu ittifakın Çin için birtakım avantajları vardır. Bir, Rusya, Çin ile benzer stratejik çıkarlara sahiptir. İki, ittifak yapmadan dünya gücü olunmaz. Bu yüzden Rusya ile ittifak dünyanın ikinci büyük gücü olmayı kolaylaştıracak imkânlar sunacaktır. Üç, Sino-Rus ittifakı BM daimi komitesinde Çin'in tek kalmasının önüne geçerek Rusya'yla birlikte bir blok oluşturmasına yardım edecektir. Dört, Rusya ile ittifak, Asya-Pasifikte Japon militarizminin tekrar yükselmesini engellemeye yardımcı olacaktır (Huasheng, 2015: 225). Xuetong, ortak kader topluluğu çağrısını askeri ittifaklara dönüşecek bir girişim olarak değerlendirse de, resmi söylemde ittifak yapmama prensibinin terkedildiğine dair bir sinyal yoktur. Xi Jinping, Çin ile Rusya arasında 15 yıl önce yapılan iyi komşuluk, dostluk ve işbirliği anlaşmasının ittifak yapmama, çelişmemezlik (non-contradiction), üçüncü tarafı hedef almama prensiplerinin mevcut ilişkiler için hala temel oluşturduğunu ifade etmektedir (Fmprc,2016). Ruonan ve Feng, resmi söylemde ittifak yapmama prensibine vurgu yaparken, akademik tartışmalardaki alternatif fikirlerinde baskılanmadığını iddia etmektedir. Bu yüzden ittifak üzerine yapılan akademik tartışmalar hükümet tarafından benimsemeyi bekleyen bir serbest pazar modeli etrafında ele alınmalıdır (Ruonan ve Feng, 2017:168). Revizyonistlerin fikirleri etrafinda bir öngörü yapılacak olursa Çin'in ittifak politikasının temel aktörü Rusya olacaktır. Çin'i ittifak politikası izlemeye itecek sebep sadece coğrafi olarak özellikle Doğu Asya'da ABD tarafından kısıtlanması değildir. Yükselen güç Çin'in kendi bölgesinde başka bir güç tarafından çevrelenmesi ve buna karşı bir oluşum içine girilmemesi aynı zamanda ulusal kamuoyunda da bir rahatsızlık yaratmaktadır. Çünkü büyük güç olmak sadece ekonomik alanda değil, siyasi ve askeri alanlarda da 
birtakım iddialarda bulunabilmeyi gerektirmektedir. $\mathrm{Bu}$ nedenle, Revizyonistlerin fikirleri, Çin'de yükselen popüler milliyetçiliğin bir tezahürü olarak değerlendirilebilir. Uzun vadede Çin diş politika karar alıcılarının, hem ulusal hem de uluslararası alandan gelen bu baskıya karşı ittifak arayışları içine girmesi kaçınılmaz görünmektedir.

\section{Extended Summary}

\section{Non-alliance Principle in Chinese Foreign Policy: Academic Debates}

\section{Introduction}

The principle of non-alliance in Chinese foreign policy is an important component of keeping low profile strategy (tao guang yang hui) of Deng Xiaoping. Deng Xiaoping declared in 1982 that China's foreign policy strategy was aimed at independence and peace, and the policy of nonalliance was officially announced. The keeping low profile strategy was also continued with partial changes by Jiang Zemin and Hu Jintao. The first official challenge to the keeping low profile strategy has been with $\mathrm{Xi}$ Jinping's striving for achievement (fen fa you wei). The strategy of striving for achievement in Chinese foreign policy is expressed in four characters. The "Qin" principle, which is the first of the four characters of the new strategy, means not only to establish closer relations with neighbors but also do not remain neutral to regional affairs. However, the principle of nonalliance of the keeping low profile strategy has not been totally abandoned. Therefore, academic debates provide an important basis for whether or not there will be a change in the policy of non-alliance.

\section{Non-Alliance Debates in Chinese International Relations Academy}

Foreign policy debates in the Chinese academy are more dynamic and complex than the framework drawn by government. In this study, the debates on the principle of non-alliance in the Chinese Academy of International Relations will be addressed around the free market community, which is trying to produce alternative policies, and epistemic community that support government policies. In 2009, the Obama administration's "Asia Pivot" strategy brought the principle of non-alliance 
to the agenda of the Academy. The Asian Pivot was considered as a strategy to expand US hegemony in the Asia-Pacific region, and the alliance has come to the fore again as an option in security strategies. Chinese academics' views on non-alliance principle can be divided into 3 categories. These are orthodoxy, revisionists and moderates, respectively.

\section{Orthodoxy}

Advocates of China's principle of non-alliance argue that China's power is not enough to build alliance system, or other countries will not be willing to form alliances with China. Ling Shengli argues that military alliances have heavy costs as well as benefits. Because of this, Shengli thinks that the non-alliance is the best strategy for the rising power of China. Qin Yaqing focuses on national capacity disparities and power gap between the US and China. Yaqing claims that the principle of non-alliance will continue as a key feature of China's foreign policy. According to him, it is unlikely that China will support its rising power identity with strategic alliances, regardless of who the potential allies will be. In the Orthodoxy group there are also academics who support the alliance with the US. Wang Jisi argues that the Sino-US rivalry in East Asia can easily turn into a zerosum game. If China moves towards the West (West Asia), potential cooperation between the US and China will increase in areas such as investment, energy and terrorism. Because of that, Western strategy is the only way to sustain geopolitical competition without conflict. Another name advocating cooperation with the US is Tang Shiping. According to Shiping, the security strategy is the result of a social learning process that changes depending on China's interaction with the norms and institutions of the international system. China has many neighboring countries and the region is the area of interest of great powers. Therefore, the geographical location of China restricts the aggressive realist strategy. According to him, China should pursue a defensive security strategy instead of an aggressive policy.

\section{Revisionists}

The alliance supporters evaluate Obama's Asia Pivot policy as a strategic design to balance China's rise both economically and militarily, or to surround China. Li Daguang expresses that China's policy of non-alliance is the result of Cold War era alliance and relationship forms based on East- 
West antagonism. But this policy does not mean that China will not establish friendship relations or participate in regional security organizations. Yan Xuetong is another important person who advocates that China should make an alliance. According to Xuetong, an alliance is a traditional strategy that has been practiced since ancient times by great powers to achieve leadership in the international arena. Therefore, if China sees national revival as a foreign policy goal, it should abandon its policy of non-alliance that has been adopted since 1982. Xuetong emphasizes that the struggle between the US and China will grow in size, but this struggle will not take place in the Cold War patterns. Xuetong describes the relationship between the US and China as superficial friendship. But this form of relationship makes it difficult to establish strategic trust between the two countries. If China establishes a network of alliances, it is difficult for the US and China to maintain a superficial friendship relationship. Therefore, Xuetong suggests superficial enmity for the US and China. Xuetong explains the superficial enmity with the concepts of positive struggle and preventive cooperation. Positive political struggle will present two development models to the world like the USA and China. Preventive security cooperation between the two countries will contribute to world peace.

\section{Moderates}

Moderates think that the principle of non-alliance should not be abandoned altogether. Moderates' ideas are issue-specific coalitions, quasi alliances and strategic partnerships. The idea of semi-alliance is an important alternative to non-alliance and pro-alliance views, as it directly prioritizes military co-operatives. Sun Degang, a supporter of the idea of a quasi-alliance, expressed a strategy in international security co-operation, based not only on official alliances but also on informal security arrangements. According to Sun, the quasi-alliance is a permanent or temporary unofficial security cooperation based on tacit agreement between one or more international political systems, not on the official collective defense pacts. Sun claims that China is following a quasi-alliance-based foreign policy strategy, not the principle of non-alliance. 


\section{Conclusion}

Apart from the Orthodoxy group, revisionists and moderates are in favor of China's alliance with other states. But moderates do not offer an alternative policy proposal because they define the quasi-alliance as China's current security strategy. In this respect, the ideas of the revisionists provide important clues as to future direction of China's alliance policy. According to the revisionists, the potential ally is primarily Russia and alliance with Russia has some advantages for China. 1) Russia has similar strategic interests with China. 2) The alliance with Russia will offer the opportunity to make China the world's second great power. 3) The Sino-Russian alliance will prevent China from being alone in the UN permanent committee. The ideas of the revisionists can be seen as a manifestation of rising popular nationalism in China. In the long term, it seems inevitable that Chinese foreign policy decision-makers are seeking alliances against this pressure coming from both national and international field.

\section{Kaynakça}

\section{Kitaplar}

Campayo, M.B. (2016). China's non alliance strategy: facing the XXI. century. African Journal of Political Science and International Relations, 10(8), 105-110.

Cheng, J.Y.S., Zhan, F.W. (2009). Chinese foreign relations under Mao and Deng: A systematic and comparative analysis. Kasarinlan. Philippine Journal of Third World Studies, 14(3), 95-99.

Huasheng, Z. (2015). Should China and Russia become allies? İçinde S. Binhong (Ed.) China Under Xi Jinping Its Economic Challenges and Foreign Policy Initiatives. (ss. 220-240). BRILL Publishing.

Jisi, W. (2014). Marching westwards: the rebalancing of China's geostrategy. İçinde S. Binhong. (Ed.), The World in 2020 According to China: Chinese Foreign Policy Elites Discuss Emerging Trends in International Politics (ss. 129-136). BRILL Publishing.

Ruonan L., Feng, L. (2017). Contending ideas on China's non alliance strategy. The Chinese Journal of International Politics, 10(2), 151171. 
Shengli L. (2013). Zhongguo weishenme bujiemeng? Waijiao Pinglun, No. $3,20-33$.

Sorensen, C. T. (2015). The significance of Xi Jinping's Chinese Dream for Chinese foreign policy: from tao guang yang hui to fen fa you wei. Journal of China and International Relations, 3(1), 53-73.

Sun, D. (2009). Brothers indeed: Syria-Iran quasi alliance revisited. Journal of Middle Eastern and Islamic Studies (in Asia), 3(2), 67-80.

Sun D. (2011). Lun zhun lianmeng zhanlue, Shijie Jingji yu Zhengzhi, No.2, $55-74$.

Xuetong, Y. (2010). The instability of China-US relations. The Chinese Journal of International Politics, 3(3), 263-292.

Xuetong, Y. (2012). Is Russia reliable? International Economic Review, 3, 21-25.

Xuetong, Y., Qi, H. (2012). Football game rather than boxing match: ChinaUS intensifying rivalry does not amount to cold war. The Chinese Journal of International Politics, 5(2), 105-127.

Xuetong, Y. (2013). Strategic cooperation without mutual trust: a path forward for China and the United States. Asia Policy, 15(1), 4-6.

Xuetong, Y. (2014). From keeping a low profile to striving for achievement. The Chinese Journal of International Politics, 7(2), 153-184.

Yaqing, Q. (2008). International factors and China's external behaviour. İçinde P. Kerr, S. Harris, Q. Yaqing (Eds.), China's New Diplomacy: Tactical or Fundamental Change (ss. 33-53). Palgrave Macmillan.

Yaqing, Q. (2014). Continuity through change: background knowledge and China's international strategy. The Chinese Journal of International Politics, 7(3), 285-314.

Zhang, F. (2012). China's new thinking on alliances. Survival, 54(5), 129148.

\section{Makaleler}

Feng H. , He, K. (2016). Why Chinese IR scholars matter: understanding the rise of China through the eyes of Chinese IR Scholars. GriffithTsinghua Conference, 11-12 Aralık, Pekin.

Zhongping, F. , Jing, H. (2014). China's strategic partnership diplomacy: engaging with a changing world. ESPO Working Paper, No.8. 


\section{Dergiler}

Feng, Z. (2008). China rise will be peaceful: how unipolarity matters. İçinde R.S. Ross, Z. Feng (Eds.), China's Ascent: Power, Security and the Future of International Politics (ss. 34-55). Cornell University Press.

Shiping, T. (2008). From offensive to defensive realism: a social evolutionary interpretation of China's security strategy. İçinde R.S. Ross, Z. Feng (Eds.), China's Ascent: Power, Security and the Future of International Politics (ss. 141-163). Cornell University Press.

Xiaoping, D. (1994). International situations and economic problems, 3 March 1990. Selected Works of Deng Xiaoping. Cilt III. Beijing: Foreign Languages Press.

\section{Web Siteleri}

CCICED, (2013). Important speech of Xi Jinping at peripheral diplomacy work conference, 16 Eylül 2017'de http://www.cciced.net/cciceden/ NEWSCENTER/LatestEnvironmentalandDevelopmentNews/20131 0/t2013 1030_82626.html adresinden erişildi.

Daguang, L. (February, 2012). Non-aligned policy does not mean make friends. Hidden Harmonies China Blog. 12 Eylül 2017'de https://blog.hiddenharmonies.org/2012/03/08/li-daguang-nonaligned-policy-does-not-mean-china-cannot-make-friends/ adresinden alınmıştır.

Feng, Z. (2017). China's North Korean liability. Foreign Affairs, 16 Eylül 2017'de https://www.foreignaffairs.com/articles/china/2017-07-11/ chinas-north-korean-liability adresinden alınmıştır.

Full text of Jiang Zemin's report at 16th party congress, IX. The international situation and our external work ". (2002, November). China Org.Cn. 12 Eylül 2017'de http://www.china.org.cn/english/ features/49007.htm adresinden alınmıştır.

Sheng, Y. (2016). China, Russia semi alliance to launch drills in South China Sea. Global Times. 20 Eylül 2017'de http://www.globaltimes.cn/content/997153.shtml adresinden alınmıştır. 
Shiping, T. (2003). The rise of China as a security linchpin, Asia Times, 15 Eylül 2017'de http://www.atimes.com/atimes/China/EF21Ad04. html adresinden alınmıştır.

Xi Jinping: China to further friendly relations with neighboring countries. (2013). Xinhua, 18 Eylül 2017'de http://news.xinhuanet.com/ english/china/2013-10/26/ c125601680/.htm adresinden alınmıştır.

$\mathrm{Xi}$ Jinping attends commemoration marking the 15th anniversary of the signing of treaty of good-neighborliness and friendly cooperation between China and Russia and delivers important speech (2016). 18 Eylül 2017'de http://www.fmprc.gov.cn/mfaeng/zxxx662805/ t1375792.html adresinden alınmıştır.

Xu, D. (2012). Zhong'e ying goujian ouya da lianmeng zuzhi meiguo tulu ruoguo. Huanqiu Shibao, 12 Eylül 2017'de http://opinion. huanqiu.com/roll/ 2012-01/2385635.html adresinden alınmıştır. 